\title{
Municipal Electrician Dies after Falling out of an Aerial Lift Truck's Raised Bucket after It Was Struck by a Semi-Tractor Trailer - Massachusetts
}

Release Date: April 15, 2014

Investigation: \# 12-MA-013-01
Massachusetts Department of Public Health Occupational Health Surveillance Program

\section{SUMMARY}

On June 19, 2012 a 63-year-old male municipal signal operator/electrician (victim) was fatally injured when he fell out of a vehicle-mounted aerial lift's raised bucket. The victim and one coworker were at a four-way intersection replacing a traffic signal bulb. The victim was inside the raised bucket accessing the cantilevered traffic signal when a tractor-trailer driving through the intersection struck the raised bucket. The victim was ejected out of the bucket and fell approximately 17 feet to the roadway below. A call was placed for Emergency Medical Services (EMS) by the driver of the tractor-trailer. Within minutes EMS and the local police arrived at the incident location and the victim was transported to a local hospital where he was pronounced dead.

Contributing factors identified in this investigation included: no fall protection used when working from a raised aerial lift bucket; positioning of the aerial lift truck that allowed vehicles to pass under the raised bucket; and improper work zone set up including inadequate quantity and positioning of temporary traffic control devices.

The Massachusetts FACE Program concluded that to prevent similar occurrences in the future, municipalities should:

- Provide and ensure that fall protection is used when working from an aerial lift truck's raised bucket/platform;

- Ensure that when performing work in roadways that work zones are set up, at a minimum, in accordance with the Manual on Uniform Traffic Control Devices (MUTCD), Part 6, developed by the U.S. Department of Transportation Federal Highway Administration;

- Ensure that employees' exposure to moving traffic is minimized when working in and around roadways by developing temporary traffic control plans, which never allow traffic to pass underneath raised aerial lift buckets/platforms;

- Provide and ensure that employees working along roadways wear the appropriate American National Standard Institute (ANSI) compliant high visibility safety apparel; 
- Provide work zone safety training for all employees who will be required to complete tasks while in proximity to roadways;

- Ensure that each department develops, implements, and enforces a comprehensive health and safety program that includes hazard recognition and avoidance of unsafe conditions; and

- Provide work environments that, at a minimum, meet all relevant Occupational Safety and Health Administration (OSHA) regulations and industry accepted standards of practice.

In addition, manufacturers of aerial lifts and employers should:

- Consider using contrasting colors and installing strobe lights along the booms of aerial lifts.

\section{INTRODUCTION}

On June 19, 2012, the Massachusetts FACE Program was alerted by the local media that earlier that same day a city employee had died from injuries sustained when he fell out of an aerial lift truck's elevated bucket when the bucket was struck by a tractor-trailer. An investigation was initiated and on August 23, 2012, the Massachusetts FACE Program and a representative from the Massachusetts Department of Labor Standards (DLS) traveled to the city and met with representatives from the municipal police department to discuss the incident. Photographs were taken of the aerial lift truck and incident location.

\section{EMPLOYER}

The employer is a municipal police department for a Massachusetts city with more than 80,000 residents. The department employed two people in the signal division, the victim and a coworker. Their main task was to maintain the traffic signals in the city. The city's signal division employees typically work 8 hours per day, starting at 7:30 a.m. and ending at 3:30 p.m., Monday through Friday. The signal division employees are routinely on call.

\section{WRITTEN SAFETY PROGRAMS AND TRAINING}

At the time of the incident, the department's signal division did not have a written safety and health program. Fall protection, including a body harness and lanyard, was available for the aerial lift operator and was kept with the truck. Annual health and safety training was not routinely performed. During the site visit, the department reported that they were in the process of developing procedures for signal division employees for the safe completion of tasks such as accessing cantilevered traffic signals.

\section{VICTIM}

The victim was a 63-year-old male municipal worker and had been employed as a signal operator/electrician by the police department for approximately 30 years. The victim had a current state-issued hoisting license and a journeyman electrician license. Signal division employees, including the victim, were part of a collective bargaining unit. 


\section{INCIDENT LOCATION}

The incident occurred at a four-way intersection located in a primarily residential section of the city. The intersection is made up of a main roadway and side street that crosses the main roadway (Figure 1). The area around the intersection has no significant grade, is relatively straight and is designated as a 30 mile-per-hour speed zone. The main roadway has one travel lane for each direction. The primary travel direction of the main roadway is north and south, but at the incident location the roadway runs east and west. There are multiple painted roadway markings in the area. The main roadway's two travel lanes are separated by solid double yellow painted lines and there are painted fog lines at the main roadway edges. The side street runs north and south and does not have many roadway markings. At the intersection, each travel lane has painted white traffic stop lines and there are two crosswalks; one across the main roadway and one across the side street. The incident location is a heavily traveled area with houses on the south side of the intersection and a school and an undeveloped lot on the north side.

The intersection has two cantilevered traffic signal structures, one of which was being accessed at the time of the incident. The base of the cantilevered structure that was being accessed is located beyond the shoulder of the roadway on a grassy area. The vertical pole section of the base reaches a height of approximately 18 feet (Figure 2). The cantilevered section is fastened to the top of the vertical pole and extends out over the eastbound lane of the main roadway. The end of the cantilevered section over the intersection has two traffic signals attached. The distance between the bottom of these traffic signals and the roadway below is 15 feet seven inches. At the time of the incident the traffic signals were operating on a regular cycle.

\section{VEHICLES}

The aerial lift truck's chassis and aerial lift body were both manufactured in 2009 and were white in color (Figure 3). The truck was equipped with dual rear wheels and had a gross vehicle weight rating of 5,897 pounds. The truck's telescoping and articulating boom platform had a height rating of 35 feet. There were two sets of controls for the movement of the truck's boom/bucket. One control was mounted to the bucket itself and the other control was mounted on the truck's body at the ground level along with an emergency stop. The vehicle was equipped with blue light-emitting-diode (LED) strobe lights located at the front and rear of the truck and two rotating orange beacon lights at the base of the boom. There was a fall protection anchor point located at the truck's bucket along with a danger decal warning of the fall hazard and the need to use fall protection (Figure 4). A body harness and lanyard were stored in the aerial lift truck.

The vehicle that struck the aerial lift truck's bucket was a four axle, 14-wheel semi-tractor trailer manufactured in 1999. The tractor trailer had a gross vehicle weight rating of 54,000 pounds. The enclosed trailer section of the semi-tractor trailer had a height of 13 feet 6 inches.

\section{INVESTIGATION}

It was daylight at the time of the incident. The temperature was 69 degrees Fahrenheit and it was overcast with no precipitation and a light wind. The victim and his co-worker arrived at the intersection at about 1:30 - 1:45 p.m. to perform maintenance on the cantilevered traffic signal. 
They each drove a vehicle to the intersection: the aerial lift truck and a van. Once at the intersection, the aerial lift truck was stopped just east of the intersection and parked at the edge of the main roadway's eastbound travel lane facing east. The van was parked at the edge of the side street to the south of the intersection and was facing south.

Two traffic cones were positioned behind the aerial lift truck to shift eastbound traffic to the north. A third traffic cone was positioned behind the van. All of the traffic cones were 28 inches tall and orange with two white reflective stripes around the tops of the cones. The aerial lift truck had its blue LED strobe lights and two rotating orange beacon lights on while stopped. The van was equipped with a blue light signal bar that was also on.

At the time of the incident, the victim was not wearing high-visibility safety apparel or personal fall protection equipment. The victim climbed into the truck's bucket and raised and extended the boom and bucket out over the active roadway's eastbound travel lane. The truck's boom was extended at about a 45 degree angle to the outer traffic signal. The bottom of the bucket was raised approximately twelve feet above the roadway. At this same time, the co-worker was standing behind the aerial lift truck with his back to the oncoming traffic to assist the victim in the maintenance task.

As the victim was working on the traffic signal a semi-tractor trailer was traveling east on the main roadway in the eastbound lane approaching the intersection and had a green traffic light at the intersection. According to the police report, the tractor trailer driver reported that he noticed the aerial lift truck parked on the side of the roadway, but did not notice the raised bucket. The tractor trailer driver veered to the left of the roadway's center line to keep away from the parked truck. As the tractor trailer entered the intersection the cab passed underneath and cleared the raised bucket. When the semi's trailer section reached the raised bucket, the trailer impacted the bucket causing the bucket to bounce up. The victim was ejected out of the bucket and fell approximately 16 feet to the asphalt roadway below.

The driver of the semi-tractor trailer felt the impact, then noticed the victim in the roadway and pulled the semi-tractor trailer over. The driver then immediately placed a call for Emergency Medical Services (EMS) and exited the cab to assist the victim. Within minutes EMS and the local police arrived at the incident location, and the victim was transported to a local hospital and then to a trauma center at a larger hospital in a neighboring state where he was pronounced dead that same day.

At the time of the site visit, the police department was developing procedures for accessing traffic signals. Reportedly, these procedures were going to include wearing personal fall protection equipment when positioned inside a raised aerial lift truck's bucket, new signage to warn motorists of work in the roadway, and the development of task work plans that must be approved 24 hours before the scheduled work. The work plans will include work zone set up and positioning of equipment. 


\section{CONTRIBUTING FACTORS}

Occupational injuries and fatalities are often the result of one or more contributing factors or key events in a larger sequence of events that ultimately result in the injury or fatality. The Massachusetts FACE team identified the following contributing factors in this incident.

- No fall protection used when working from a raised aerial lift.

- Positioning of the aerial lift truck that allowed vehicles to pass under the raised bucket.

- Improper work zone design and set up, including inadequate positioning and quantity of temporary traffic control devices to warn motorists of the work occurring within the roadway.

\section{CAUSE OF DEATH}

The medical examiner listed the cause of death as blunt trauma of head and torso.

\section{RECOMMENDATIONS/DISCUSSION}

\section{Recommendation \#1: Municipalities should provide and ensure that fall protection is used when working from an aerial lift truck's raised bucket/platform.}

Discussion: In this incident, the victim was working from a raised aerial lift truck without fall protection. The provided fall protection was stored in the truck, but the use of it was not enforced. Fall protection should be used whenever working from an aerial lift truck's raised platform. ${ }^{1}$ It is the employers responsibility to ensure fall protection is available when needed, and is being worn and used properly by employees. Employers should also provide training on when and how to properly use the provided fall protection. There are two main types of fall protection systems that can be used with aerial lift trucks.

1) Restraint Systems. A restraint system is the preferred method of protection since it allows the worker to move around the bucket and will prevent the worker from falling out of the bucket. The components of a restraint system include either a body belt or a harness (harness is recommended) connected to a lanyard. The lanyard must not be longer than two feet and the other end of the lanyard must be attached to an anchor point. Aerial lift truck anchor points are usually located on either the truck's bucket or boom. In this case, the anchor point was located on the truck's boom.

2) Fall Arrest Systems. A fall arrest system is intended to stop a falling worker before they strike a lower level and must not allow the worker to fall more than six feet. Fall arrest systems require the use of a body harness (body belts should never be used with a fall arrest system). The body harness connects to a lanyard and the other end of the lanyard connects to an anchor point. Not all aerial lift trucks are designed for the use of fall arrest systems. Therefore always check with the aerial lift truck manufacturer to see which fall protection system should be used. 


\section{Recommendation \#2: Municipalities should ensure that when performing work in roadways that work zones are set up, at a minimum, in accordance with the Manual on Uniform Traffic Control Devices (MUTCD), Part 6, developed by the U.S. Department of Transportation Federal Highway Administration.}

Discussion: Employees who are required to complete tasks in and around roadways face multiple hazards, one of which is being struck by oncoming motor vehicles. In this case, two orange traffic cones were placed behind the aerial lift truck to warn approaching vehicles of the work being performed within the roadway. This was not an adequate traffic control measure for this task.

The U.S. Department of Transportation's (DOT) Manual on Uniform Traffic Control Devices (MUTCD) sets forth the basic principles that govern the design and usage of traffic control signs and devices. ${ }^{2}$ Part 6 of the MUTCD provides specific work zone designs to be used during roadway construction, maintenance, and utility operations. To help ensure employee safety while performing these and other roadway operations, employers should follow the MUTCD minimum standards and guidelines in Part 6. These standards and guidelines will help determine the appropriate number and locations of traffic control devices, such as warning signs, cones, and lights.

When performing work in a roadway that will occupy a location for a few minutes up to one hour, employers should follow the short-duration roadway work application outlined in the MUTCD, Part 6G, Types of Temporary Traffic Control Zone Activities. Because most shortduration roadway work usually involves maintenance and utility based operations, the MUTCD recommends traffic control devices that have greater mobility. The MUTCD specifically states that worker safety during short-duration roadway work should not be compromised by using fewer traffic control devices. ${ }^{2}$

The MUTCD acknowledges that during short-duration work, it can sometimes take longer to set up the work zone properly. Therefore, the MUTCD suggests that appropriately colored or marked vehicles with high-intensity rotating, flashing, oscillating, or strobe lighting may be used in place of signs. In addition, the MUTCD suggests that these vehicles may be augmented with signs or arrow panels. ${ }^{2}$

\section{Recommendation \#3: Municipalities should ensure that employees' exposure to moving traffic is minimized when working in and around roadways by developing temporary traffic control plans, including never allowing traffic to pass underneath raised aerial lift buckets/platforms.}

Discussion: To ensure the safety of workers whose jobs bring them in and around roadways, employers should develop temporary traffic control plans (TCP) that outline the temporary traffic control devices to be used, how they should be set up during roadway work, and proper placement of any work equipment and vehicles. ${ }^{3}$ A TCP will not only help ensure worker safety, it will also help ensure motorist and pedestrian safety as well. TCPs should be based on the 
MUTCD as discussed in Recommendation \#2. An individual TCP should be developed for each major highway and street project.

For short duration relatively common tasks, such as accessing cantilevered traffic signals, a general TCP should be developed and modified when appropriate. A general TCP for accessing cantilevered traffic signals could include, but not be limited to:

- Assessing the work site upon arrival to determine the best location for work vehicles and mobile equipment and the appropriate number and locations of traffic control devices, such as warning signs and lights based on the MUTCD;

- Ensuring that placement and use of vehicle-mounted aerial lifts does not allow roadway traffic to pass underneath the raised aerial lift bucket/platform at any time;

- Determining if assistance in the form of traffic details or flaggers would be beneficial;

- Wearing the appropriate high-visibility safety apparel at all times;

- Facing and watching out for approaching traffic; and

- Spending as little time as possible in and around the roadway.

In this case, because large trucks, including semi-tractor trailers, routinely traveled this relatively narrow two lane roadway, assistance in the form of a traffic detail or a flagger should have been considered as a part of the TCP.

\section{Recommendation \#4: Municipalities should provide and ensure that employees working along roadways wear the appropriate American National Standard Institute (ANSI) compliant high visibility safety apparel.}

Discussion: Employees that routinely work in and along roadways can face many hazards while working. One hazard is routinely being in close proximity to motor vehicle traffic, usually with no barriers between them and the moving vehicles. In this case, the clothing being worn by the victim reportedly did not contain reflective material. Although wearing high-visibility safety apparel might not have prevented this specific incident, the victim was working in and around the roadway and high-visibility safety apparel should have been worn.

The Manual on Uniform Traffic Control Devices (MUTCD) states that all workers exposed to the risks of moving roadway traffic or construction equipment should wear high-visibility safety apparel. $^{2}$ The MUTCD refers to the American National Standard Institute's (ANSI) standard for High-Visibility Safety Apparel (ANSI/ISEA 107-2004). ${ }^{4}$ This standard, published by the International Safety Equipment Association (ISEA), recommends specific types of reflective equipment while working in or near moving vehicles. This standard specifies three classes of garments based on the workers' activities. These classes are:

- Class 3 garments provide the highest level of visibility for workers who face serious hazards with high task loads that require attention away from their work where traffic exceeds 50 miles per hour (mph). 
- Class 2 garments are intended for use where greater visibility is necessary during inclement weather conditions and when activities occur near roadways where traffic speeds exceed $25 \mathrm{mph}$.

- Class 1 garments (not for use along highways and streets) are intended for use in activities that permit the wearer's full and undivided attention to approaching traffic. There should be ample separation of the worker from traffic, which should be traveling no faster than 25 miles per hour.

The ANSI standard also states that a competent person designated by the employer should be responsible for selecting the appropriate class of garment for the workers. A competent person, as defined by the Occupational Safety and Health Administration (OSHA), is a person who, through training or knowledge, is capable of identifying existing and predictable hazards in the surroundings or working conditions that are unsanitary, hazardous, or dangerous to employees, and who has authorization to take prompt corrective measures to eliminate them. In addition, employers should ensure that workers are wearing the high-visibility safety apparel provided.

\section{Recommendation \#5: Municipalities should provide work zone safety training for all employees who will be required to complete tasks while in proximity to roadways.}

Discussion: Work zone safety training for municipal workers should include, but not be limited to, properly selecting and setting up the most effective work zone configuration, how to work near motor vehicle traffic in a way that will minimize exposure to moving vehicles, as well as the proper techniques for warning device usage, placement, and retrieval. Training municipal workers in roadway work zone safety should also include short-and long-duration work zone set up and design and appropriate personal protective equipment. This training would not only provide municipal workers with the knowledge to better protect themselves so tasks can be completed safely, but will also help keep pedestrians and motorists in the community safe as well. All trainings should be updated annually and documented. The documentation should include who provided the training and their qualifications, the content of the training, workers who were trained, and the assessments of workers' comprehension of the training. Employers should ensure that the trainer who provides training is qualified through education and/or experience to conduct training.

\section{Recommendation \#6: Municipalities should develop, implement, and enforce a comprehensive health and safety program that includes hazard recognition and avoidance of unsafe conditions.}

Discussion: In this case, the police department's signal division did not have a comprehensive health and safety program. A comprehensive written health and safety program for the signal division should address common hazards municipal employees face, such as electrical, fall from heights and work zone hazards. Hazard recognition and the avoidance of unsafe conditions is another area that the health and safety program should address. When developing the health and safety plan, the employer with employee participation should conduct a job safety analysis (JSA). ${ }^{5}$ 
A JSA is a technique to systematically evaluate job tasks to ensure the tasks are performed safely. It involves identifying all potential hazards and hazardous situations that could occur when performing tasks by focusing on the relationship between the worker, the task, the tools and the work environment. JSAs should be routinely performed to identify uncontrolled hazards by breaking down the tasks to be performed into steps, including the operation of any equipment and use of tools to complete the task. Each step should be evaluated to identify the hazards or potential hazards. Once hazards are identified, appropriate preventive measures should be implemented to eliminate or control these hazards.

OSHA has developed a webpage that addresses how to implement health and safety programs (www.osha.gov/dsg/topics/safetyhealth/evaluation.html). This webpage includes a link to the OSHA draft proposed safety and health program rule and to other useful links.

In addition, there is a Roadway Safety Awareness Program available in English, Spanish and Portuguese at www.workzonesafety.org/training/courses_programs/rsa_program. This program Roadway Safety + provides an overview of common hazards in highway and road construction and prevention measures that can be incorporated in to a health and safety program.

\section{Recommendation \#7: Municipalities should provide work environments that, at a minimum, meet all relevant Occupational Safety and Health Administration (OSHA) regulations and industry accepted standards of practice.}

Discussion: The federal Occupational Safety and Health Act requires private sector employers to provide workplaces that are free from recognized hazards likely to cause death or serious physical harm to employees. While private sector employees are covered by federal OSHA, public sector employees in Massachusetts are not. The Massachusetts Department of Labor Standards (DLS), in accordance with Massachusetts General Laws Chapter 149 Section 6, is charged with inspecting public sector workplaces in Massachusetts and determining what procedures and practices are required to protect workers. ${ }^{6}$ As a matter of policy, DLS references OSHA Standards as well as other consensus standards such as those developed by the American National Standards Institute (ANSI), in determining whether proper procedures are being followed to protect workers. In this case, adhering to the following OSHA standards may have prevented this incident: 29 CFR 1926.453, Aerial lifts, and 29 CFR 1926.202, Barricades, which refers to the MUTCD for design and usage of traffic control signs and devices and work zone designs. ${ }^{1,7}$

DLS has enhanced efforts to improve health and safety conditions for municipal workers by increasing incident inspections and voluntary technical assistance for municipalities. During an incident inspection if conditions are observed that could cause worker injury or illness, a written warning will be issued by DLS with an order to correct the identified hazards. If the identified hazards are not corrected within the timeframe specified in the written warning, then monetary civil penalties per condition may be issued by DLS to the employer. ${ }^{6}$ 


\section{Recommendation \#8: Manufacturers of aerial lifts and employers should consider using contrasting colors and installing strobe lights along the booms of aerial lifts.}

Discussion: The operator of the tractor-trailer indicated that he did observe the aerial lift truck in the roadway and the truck's bumper strobe lights, but it appears that that he might not have noticed the extended boom and the worker in the bucket.

Aerial lift trucks are often used in and around roadways, which can place the truck in close proximity to moving vehicles. To help make aerial lift trucks, including their booms and buckets, as visible as possible, consideration should be given to adding contrasting colors, which could also be florescent and/or reflective, to both the boom, bucket and to some areas of the truck. In addition, adding some light-emitting-diode (LED) strobe lights to sections of the boom, bucket and truck might increase both the visibility of the truck and the actual location of workers when they are working from the truck's raised bucket.

\section{REFERENCES}

1. Code of Federal Regulations [1996]. 29 CFR 1926.453. Aerial lifts. Washington DC: U.S. Government Printing Office, Office of the Federal Register.

2. U.S. DOT 2009. Manual on Uniform Traffic Control Devices (MUTCD), 2009 Edition, U.S. Department of Transportation Federal Highway Administration. http://mutcd.fhwa.dot.gov/. Date accessed: 12/16/2013.

3. NIOSH 2001. Building Safer Highway Work Zones: Measures to Prevent Worker Injuries from Vehicles and Equipment, Department of Health and Human Services, Centers for Disease Control and Prevention, National Institute for Occupational Safety and Health, DHHS (NIOSH) Publication No. 2001-128.

4. ANSI/ISEA [2004]. American National Standard for high-visibility safety apparel. New York, NY: American National Standards Institute, ANSI/ISEA 107 -2004.

5. U.S. DOL 2002. Job Hazard Analysis. Occupational Safety and Health Administration, OSHA Publication No. OSHA-3071, 2002 (revised).

6. General Laws of Massachusetts, Title XXI, Labor and Industries, Chapter 149: Section 6. Safety devices and means to prevent accidents and diseases generally; fees for structural painting.

7. Code of Federal Regulations [2002]. 29 CFR 1926.202. Barricades. Washington DC: U.S. Government Printing Office, Office of the Federal Register. 
Figure 1 - Aerial view of the intersection

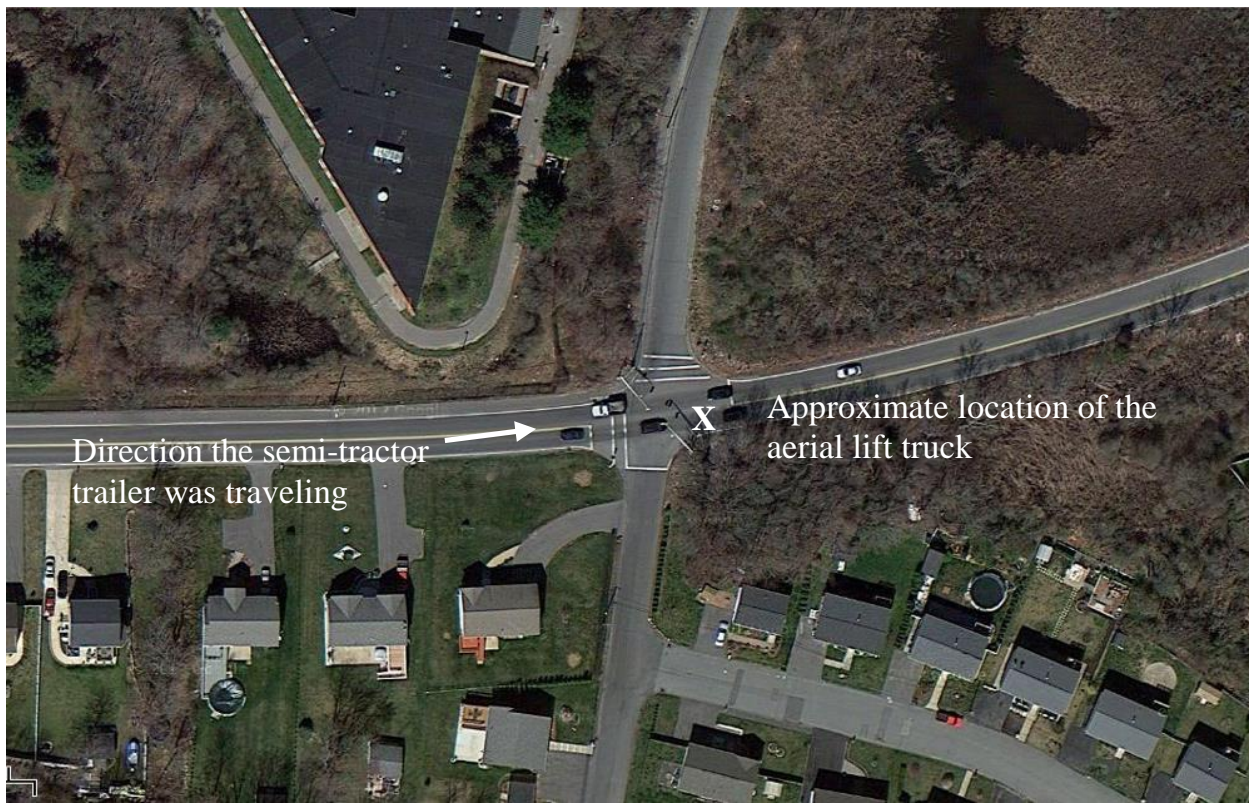

Figure 2 -Street view of the intersection looking east on the main roadway

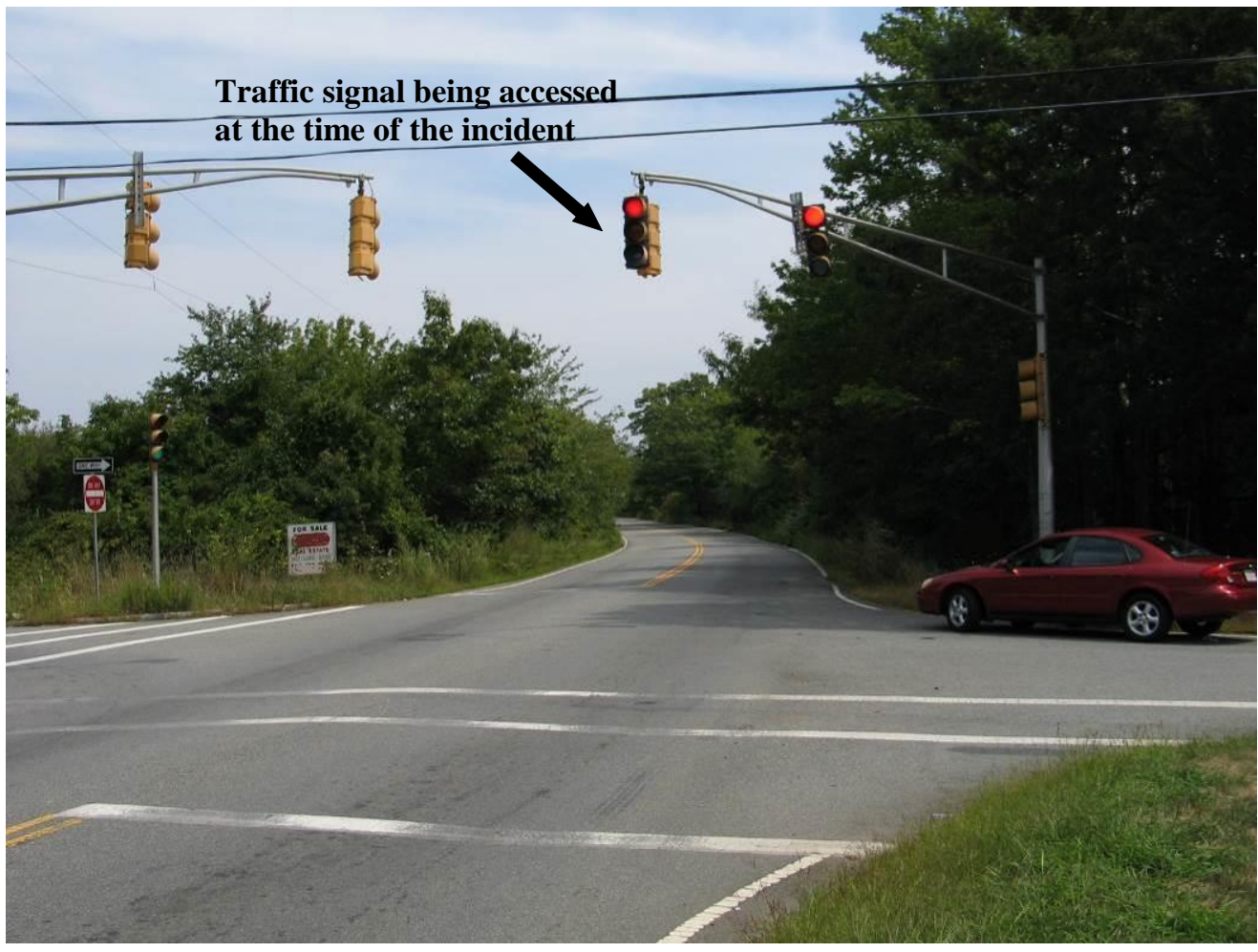


Figure 3 - Aerial lift truck involved in the incident

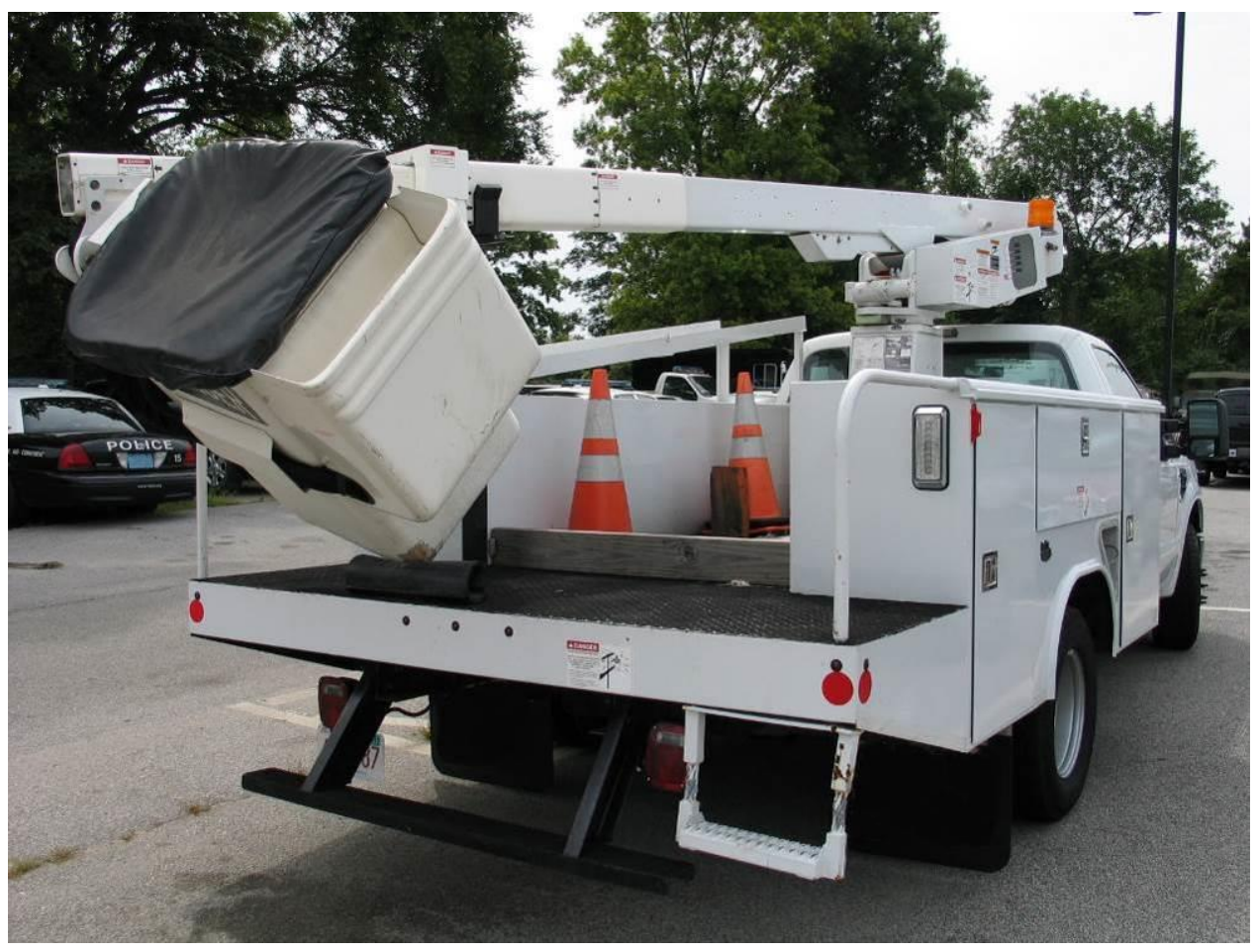

Figure 4 - Aerial lift truck's danger decals

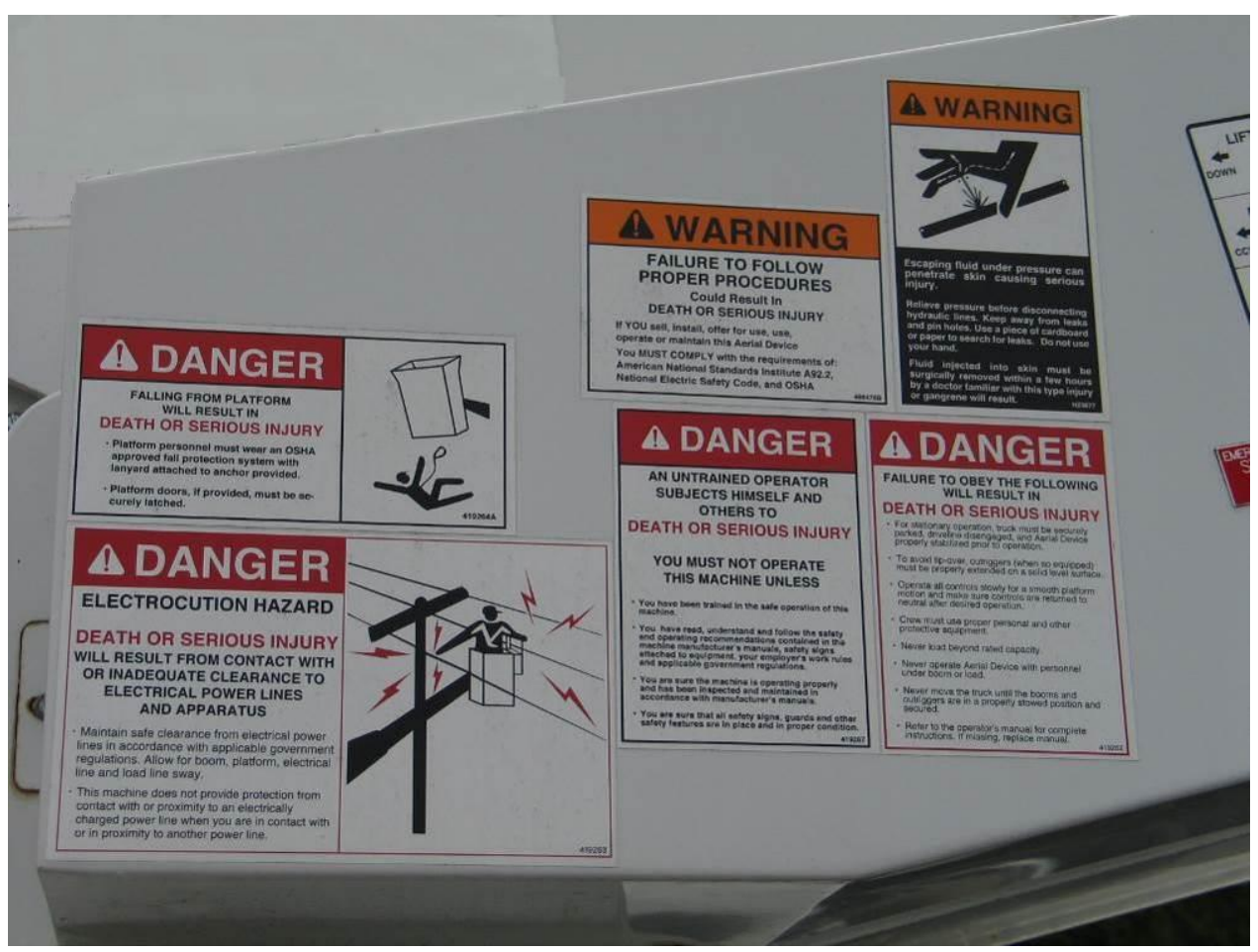


Figure 5 - Incident location after the incident showing the traffic signal, the aerial lift's raised buck and the semi-tractor trailer

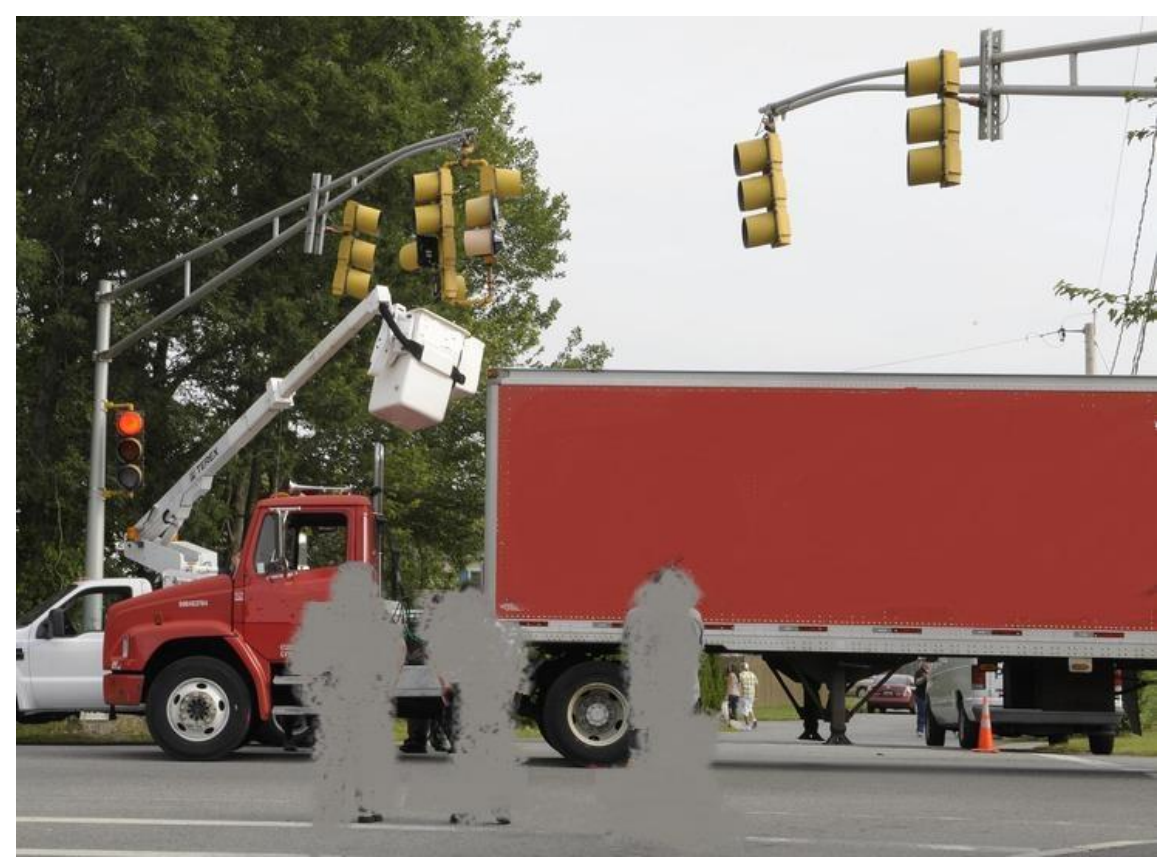

